\section{EL TRABAJO DE LAS FUERZAS ARMADAS ESPAÑOLAS Y LA CULTURA DE LA DEFENSA}

\author{
Valentina Fernández Vargas \\ Instituto de Políticas y Bienes Públicos CSIC. \\ valentina.fernandez@cchs.csic.es
}

\section{THE WORK OF THE SPANISH ARMED FORCES AND THE CULTURE OF DEFENCE}

Cómo citar este artículo/Citation: Fernández Vargas, V. (2014). "El trabajo de las Fuerzas Armadas Españolas y la Cultura de la Defensa". Arbor, 190 (765): a097. doi: http://dx.doi. org/10.3989/arbor.2014.765n1004

Recibido: 5 junio 2012. Aceptado: 2 diciembre 2013.

RESUMEN: El mundo actual vive un proceso de globalización. Eso da lugar a desacuerdos políticos que pueden originar guerras civiles o nuevos conflictos inconcebibles en el pasado, como el atentado terrorista en las Torres Gemelas de Nueva York (2001) o en la estación de Atocha de Madrid (2004). Como consecuencia ha habido intervenciones internacionales cada vez que se ha considerado necesario. Así (respetando siempre los acuerdos internacionales), las Fuerzas Armadas españolas han actuado en distintos territorios. Esas Fuerzas representan por primera vez a la sociedad española, incluidos las mujeres y los inmigrantes con especiales relaciones con España.

PALABRAS CLAVE: Globalización; nuevos atentados terroristas; intervenciones militares internacionales; participación española; representación de la sociedad española por parte del ejército español.
Copyright: (c) 2014 CSIC. Este es un artículo de acceso abierto distribuido bajo los términos de la licencia Creative Commons Attribution-Non Commercial (by-nc) Spain 3.0.

ABSTRACT: The world is currently experiencing a process of globalisation. The resulting political strife can lead to civil wars or new threats inconceivable in the past, such as the terrorist attack on the Twin Towers in New York in 2001 or the 2004 Madrid train bombings. International interventions have consequently taken place whenever they have been considered necessary. Therefore (always complying with the international agreements), the Spanish Armed Forces have been deployed in various territories. These forces represent the Spanish society for the first time, as they include both women and immigrants with special ties to Spain.

KEYWORDS: Globalisation; New terrorist attacks; International military interventions; Spanish participation; Spanish Army representing Spanish society. 
En el año 2008, en el prólogo del primer número monográfico de la revista Arbor dedicado a la Cultura de la Defensa, definíamos esta como "el grado de conocimiento que tiene el español medio sobre los temas que atañen a la Defensa Nacional" y valorábamos muy positivamente el trabajo desarrollado por el Instituto Español de Estudios Estratégicos (IEEE) para difundirla.

Ahora nos parece pertinente añadir que todo conocimiento, cualquiera que sea su nivel, para ser válido ha de ser demostrable, basarse en la experiencia, en la experimentación. Que una profesional, cuyo trabajo se ha centrado en la investigación en Historia, en Sociología, en la docencia universitaria, inicie así un artículo para una revista científica como Arbor puede parecer una obviedad casi ofensiva. Pasamos, pues, a explicar, a justificar, este inicio.

En primer lugar queremos subrayar que esta exposición va a ser breve y va a girar básicamente en torno a situaciones, a acontecimientos, acaecidos en el curso de las diversas misiones internacionales en las que ha participado, en las que participa, España. Situaciones poco conocidas - por la enorme discreción de los profesionales de las Fuerzas Armadas- y a las que hemos accedido básicamente por nuestra experiencia como directora, como ponente, de cursos, de seminarios. Todo lo cual nos permite afirmar que el profesorado militar con experiencias concretas realizaba exposiciones particularmente interesantes, en la línea que ahora nos interesa, sobre todo en los Coloquios; estas, por supuesto, reflejan experiencias personales pero que, en ningún caso, debemos considerar situaciones puntuales, anecdóticas. Tampoco ignoramos que para algunos pueden ser consideradas como marginales, en comparación con los objetivos que llevaron a las tropas españolas a desplazarse a zonas concretas.

Ahora bien, y puesto que vamos a centrarnos en actuaciones, en experiencias, acaecidas fuera de nuestras fronteras, nos parece pertinente plantear que es evidente que todos los seres vivos necesitan un espacio para vivir, para desarrollarse (Fernández Vargas y Rodríguez Toubes, 2008), que en el caso de los seres humanos pronto generó la aparición de grupos que ahora denominaremos guerreros para defender su territorio. Situación que supone, a su vez, la existencia de fronteras ${ }^{1}$.

Ahora bien, estas fronteras en un primer momento pudieron estar definidas por grandes accidentes geográficos, y nos parece pertinente citar, ahora, la Paz de los Pirineos (1659) que determinaría una de las fron- teras más antiguas de Europa: los montes Pirineos, aunque como es sabido existe un País Vasco Francés y un País Vasco Español. En otras palabras, un solo pueblo-el vasco- se vio separado por acuerdos políticos.

Si analizamos mapas modernos, podemos comprobar que las fronteras entre determinados territorios, sobre todo aquellos recientemente descolonizados, responden al trazado de paralelos y meridianos. Lo cual agudiza las tensiones. Máxime si en alguno de ellos, o entre ellos, existen grandes riquezas, o desiertos, y sus comunidades son, en todo o en parte, trashumantes.

El resultado es un mundo que si en determinados aspectos está en proceso de globalización, en otros experimenta, sufre, tensiones de larga duración, uno de cuyos resultados será el terrorismo internacional cuya característica fundamental es, en nuestra opinión, que el cuerpo del terrorista es un arma, puesto que responde al denominado terrorismo, terrorista, suicida. Ya volveremos sobre esto.

En consecuencia se han multiplicado las intervenciones internacionales, allí donde se ha considerado preciso. Y ahora nos parece pertinente recordar los atentados a las Torres Gemelas de Nueva York (2001) o los de la Estación de Atocha en Madrid (2004); es decir, la defensa de las fronteras de territorios concretos se ha trasladado a lugares impensables hace unos años.

Y esta es, en nuestra opinión, una de las razones de determinados acuerdos internacionales que, para las Fuerzas Armadas Españolas, han supuesto el despliegue en muy diversos territorios. Aunque tampoco ignoramos que en el preámbulo de la Constitución hoy vigente se indica: "colaborar en el fortalecimiento de unas relaciones pacíficas y de eficaz cooperación entre todos los pueblos de la tierra" (Hervada y Zumaquero, 1980, p. 366), en tanto que el título preliminar De los deberes y derechos fundamentales, artículo10.2, señala: "las normas relativas a los derechos fundamentales que la Constitución reconoce se interpretarán de conformidad con la Declaración Universal de los Derechos Humanos y los tratados y acuerdos internacionales sobre las mismas materias ratificados por España (Hervada y Zumaquero, 1980, p. 368), todo lo cual queda recogido en las Reales Ordenanzas para las Fuerzas Armadas hoy vigentes ${ }^{2}$. Recordemos lo que se indica en el título preliminar, Disposiciones Generales, artículo 4, Deberes de carácter general: "El militar guardará y hará guardar la Constitución como norma fundamental del Estado y cumplirá las obligaciones derivadas de las misiones de las Fuerzas 
Armadas, de su condición militar y de su sujeción a las leyes penales y disciplinarias militares. En tanto que el Título II, De la disciplina, en el artículo 48, Límites de la obediencia, subraya: "si las ordenes entrañan la ejecución de actos constitutivos de delito, en particular contra la Constitución y contra las personas y bienes protegidos en caso de conflicto armado, el militar no estará obligado a obedecerlas. En todo caso, asumirá la grave responsabilidad de su acción u omisión".

Dicho esto, añadiremos que la relación de las Fuerzas Armadas españolas con las $\mathrm{ONGs}^{3}$ que trabajan en sus zonas de despliegue ha podido ser, ha sido, muy fluida, de apoyo, de reconocimiento a su labor; y mencionaremos ahora a la doctora Mercedes $\mathrm{Na}$ varro, de Médicos del Mundo, que perdió la vida en Bosnia y cuyo nombre conocemos por militares allí desplegados.

Ahora bien, en ningún caso desearíamos que se pueda pensar que consideramos a las Fuerzas Armadas españolas como ONGs de uniforme, pues los objetivos militares son muy distintos, muy claramente definidos en los documentos políticos emanados de los Organismos que decidieron el despliegue. En dos palabras, los militares son Fuerzas Armadas y su trabajo consiste en defender, con las armas cuando es preciso, los objetivos políticos que determinaron su despliegue en áreas determinadas ${ }^{4}$. $Y$ aunque vamos a limitarnos, a centrarnos, en la experiencia de la ex Yugoeslavia -pues se trata de una Misión ya cerradanos ha parecido oportuno hacer una referencia puntual a la experiencia en Afganistán.

Según hemos escuchado a algunas militares, miembros de los cuerpos sanitarios, era relativamente frecuente que mujeres cubiertas de fístulas ${ }^{5}$, accedieran a los servicios sanitarios militares que atendían a la población civil. Y lo hacían en situaciones tan precarias que, a veces, eran transportadas en carretillas. Aunque, puntualizaban, solo acudían a estos servicios si iban a ser atendidas por mujeres ${ }^{6}$.

Cuerpos sanitarios que afrontan riesgos gravísimos, como demuestra la biografía de la soldado Idoia Rodríguez, única militar española caída en acto de servicio. Sucedió el 27 de febrero de 2007 en la provincia afgana de Herat, al estallar una mina bajo la ambulancia blindada en que viajaba, formando parte de un convoy militar. Fue la única víctima mortal. Condecorada con la Medalla OTAN, tras su fallecimiento recibió la Cruz al Mérito Militar con distintivo rojo. En su memoria se creó, en el año 2007, el Premio Soldado Idoia Rodríguez, Mujer en las Fuerzas Armadas, que hemos tenido el honor de recibir en su tercera convocatoria.
La experiencia afgana ha motivado que, como se recoge en el número 272, correspondiente a abril de 2011, de la Revista Española de Defensa, Doña Carme Chacón, ministra de Defensa en aquel momento, anunciara el 8 de marzo de 2011, coincidiendo con el Día Internacional de la Mujer, que el Observatorio de la Mujer en las Fuerzas Armadas "cambiaría su nombre por el de Observatorio Militar por la Igualdad entre Hombres y Mujeres y [...] cambiaría sus funciones para avanzar hacia la plena igualdad en los Ejércitos". Más adelante subrayaba la ministra de Defensa que "nuestros militares en sus misiones velan, siempre, por la seguridad de las mujeres" y anunciaba que "todos los contingentes españoles que se desplacen a dicho país [Afganistán] incluirán una persona responsable de género".

Pasemos ahora a exponer brevemente, como ya hemos indicado, los aspectos que constituyen el núcleo de este trabajo.

Antes recordaremos que, en 1995, los Acuerdos de DAYTON, también conocidos como Protocolo de París, ponen fin a la guerra que entre 1991 y 1995 se desarrolló en la antigua República Federal Socialista de Yugoeslavia ${ }^{8}$ y en la que intervinieron sucesivamente la ONU, la OTAN y la UE.

En 1996, la Revista Española de Defensa informa en su número 101-102, correspondiente al mes de agosto, de la visita realizada el 8 de julio por el Presidente del Gobierno de España, don José María Aznar, acompañado por el Ministro de Defensa, don Eduardo Serra y por el Teniente General don José Rodrigo, Jefe del Estado Mayor de la Defensa. Les reciben don Ricard Pérez Casado, Administrador de la Unión Europea en Mostar, don Luis Carvajal, Jefe de la Brigada española y el General Francés Xavier de Lambert, máximo responsable de la División Multinacional Sudiste. A continuación el Presidente del Gobierno de España y las personalidades que le acompañan se dirigen a la plaza de Mostar que en 1995, y en fecha tan significativa para España como el 12 de octubre, había recibido el nombre de Plaza de España y descubre el Monumento que homenajea a los dieciséis españoles y al interprete caídos durante el conflicto.

De entre los múltiples e interesantes artículos que recoge la Revista, mencionaremos ahora la entrevista a Luis Carvajal Raggio, Jefe de la Brigada Almogávares que indica: "debemos evitar la implicación personal".

Mencionaremos igualmente la entrevista al señor Pérez Casado: "[las elecciones se han llevado a cabo] sin ningún tipo de incidentes graves gracias a la co- 
ordinación perfecta entre las organizaciones musulmanas, croatas, servias, la Administración Europea e IFOR con su Brigada española". Continúa exponiendo la "dureza" de las negociaciones y subraya que su éxito constituye para la Comunidad Internacional una experiencia piloto extensible al resto de Bosnia ${ }^{9}$. Y todo ello, sin olvidar el problema de los refugiados: "cientos de miles". Ya hemos recogido, en palabras del General Carvajal Raggio, referencias a la "implicación personal" que nos parecen una buena apertura para lo que constituye el núcleo de nuestro texto.

Empezaremos por el testimonio del Teniente Coronel don José M. a Sánchez Feijóo, máximo responsable del Grupo Táctico Castillejos (Fernández, 1996) que remarca que la buena acogida a las tropas españolas no se ha limitado a los jefes militares y recuerda que si en Mostar era habitual ver grupos que se abalanzaban sobre los BMR en busca de un puñado de caramelos, esta situación se repetiría también en el sur de Bosnia-Herzegovina. Y menciona que el Grupo Castillejos compró 4.000 marcos de insulina para el Hospital de Trevinje y que las ambulancias de este centro cuentan con el apoyo del destacamento cuando tienen que trasladar enfermos a los servicios de hemodiálisis de Montenegro. $Y$ todo ello sin olvidar que han repartido por las calles de Trevinje folletos informativos con consejos de información vial que advierten del peligro que constituyen las minas. O la colaboración en la reconstrucción del Puente de Tito.

Estos testimonios escritos, los Coloquios de los distintos actos académicos en los que hemos participado, constituyen ejemplos de excepción para conocer la relación entre los militares españoles y la población civil; relación que, insistimos, no podemos reducir a lo anecdótico pues, por ejemplo, la Resolución $1325^{10}$ del Consejo de Seguridad de la ONU marca entre sus objetivos "la interacción entre las organizaciones locales y los estados miembros", interacción cuyo primer nivel es, qué duda cabe, personalizado.

Incluiremos ahora algunos testimonios sobre actuaciones personales, personalizables; hemos escuchado reiteradamente que los soldados españoles, conscientes de las necesidades, de las carencias, del hambre de la población civil no comían en público y, si lo tenían que hacer, repartían sus raciones, sus yogures, entre la población, sobre todo mujeres y niños que, conocedores de tal práctica y de sus horarios, formaban cola para recibirlos. Colas que, en más de una ocasión, fueron ametralladas por francotiradores. La respuesta española consistió no en suspender tal práctica sino en hacerla en horas aleatorias, individualizándola.
Igualmente, antes de que el terrorismo islamista hiciera su aparición, no era raro que si las tropas españolas motorizadas se cruzaban en las carreteras con población civil huida, subieran a los más débiles a los transportes en los que había espacio. Hoy los atentados suicidas ${ }^{11}$ lo han hecho imposible.

Pero además de actuaciones más o menos puntuales, que podemos considerar fruto de circunstancias muy concretas, hay otras que podemos considerar con proyección de futuro, que permanecen cuando ya las Fuerzas Armadas han salido del territorio. Es decir, no se olvidan de los lazos establecidos. Es el caso del colegio Los Rosales, cuyo nombre en español es el reconocimiento al apoyo recibido por su fundadora y directora Jafna Rebac y que acoge a personas, cualquiera que sea su origen, con discapacidades diversas. Ya volveremos sobre esto.

Cuando en octubre del año 2010 el último contingente español inicie el repliegue ${ }^{12}$, la Ministra de Defensa, a continuación del acto oficial, se trasladará al pueblo de Mostar donde, acompañada del Alcalde de la ciudad, realizará una ofrenda floral en el monumento a los caídos de la plaza de España, recordará que "la ciudad fue el centro de gravedad del despliegue de las tropas españolas" y destacará "que la plaza de España quedará como un espacio de convivencia para las futuras generaciones". España, dijo doña Carme Chacón, no abandonará Mostar porque nuestra historia común nos ha unido para siempre. "Mostar quedará en el corazón de España, como España quedará en el corazón de Mostar", concluyó.

El premio extraordinario de Defensa del año 2010 fue concedido a los 46.000 militares desplegados en la zona de los Balcanes desde 1992. Pues bien, la dotación económica del mismo fue donada por los galardonados al colegio Los Rosales. Y se trata de una información directa, pues estuve presente en el acto.

Concluimos. Esperamos que los hechos expuestos, todos ellos comprobables, demostrables, avalen nuestro planteamiento inicial y, por lo tanto, que el positivo reconocimiento a las Fuerzas Armadas, recogido por ejemplo en los Informes del Centro de Investigaciones Sociológicas (CIS) no responde a eficaces políticas propagandísticas, sino a su actuación en las misiones internacionales, aunque también, es indiscutible, a su trabajo en el territorio nacional en caso de catástrofes naturales, de incendios. Y aquí y ahora es ineludible al menos mencionar a la Unidad Militar de Emergencia (UME), a las bajas, sobre todo a los fallecimientos, de sus componentes que no dudan en intervenir, en arriesgar su vida allí donde es necesario. 
Añadamos a esto la correcta interacción entre las Fuerzas Armadas y la sociedad de que proceden pues, por primera vez en la historia de España, son una imagen especular de la sociedad de la que proceden, en las que trabajan hombres y mujeres, españoles o inmigrantes, procedentes estos últimos de aquellos países con los que España tiene especial vinculación histórica.

Por todo ello, y como ya hemos escrito en nuestro trabajo sobre la Resolución 1325 (Fernández Vargas, 2011b), creemos que "aquellos de los objetivos [...] sobre la interacción entre las organizaciones locales y los estados miembros, en este caso España, representada por sus Fuerzas Armadas, el esfuerzo diplomático y la ayuda al desarrollo, se han cumplido". Al igual que esperamos haber cumplido con nuestro planteamiento inicial y que este texto, a pesar de su brevedad y planteamiento, constituya una aportación válida para la consolidación y difusión de la Cultura de la Defensa en España.

Cuando ya habíamos concluido este artículo, el diario El País publica en su primera página una foto terrible según la cual "un grupo de soldados españoles maltrató en 2004 a dos prisioneros irakíes en la base de Diwaniya, la base del Ejercito en Irak ${ }^{13 "}$.

Esta situación que, por supuesto, rechazamos no anula lo que hemos expuesto anteriormente y tal es también la opinión de El País, expuesta en el editorial "Torturas en Irak"14, en el que después de señalar cómo, a diferencia de lo ocurrido en EE.UU. tras el 11S, "el mando militar español invocó la Convención de Ginebra IV y protocolos adicionales al impartir instrucciones sobre el trato a prisioneros [...] tenemos todo el derecho a conocer qué sucedió con estos dos arrestados, así como con varias decenas más que pasaron por las celdas de Base España. Las brutalidades cometidas por un puñado de soldados no cuestionan a los casi 5.000 españoles que pasaron por Irak [...] [ni] a los 130.000 que han participado en las diferentes misiones en el exterior".

A todo ello añadiremos que la difusión del vídeo del que procede la foto, por diversas cadenas de televisión, ha de enmarcarse en la libertad de expresión, en el derecho a conocer que tienen, que tenemos, todos los miembros de la sociedad española. En esta misma línea insiste El País ${ }^{15}$, periódico que días después ${ }^{16}$ informa de que el Ministerio de Defensa admite que los brutales acontecimientos podrían haberse grabado en Irak.

Finalmente, este mismo diario recoge unas declaraciones de José Luis Rodríguez Zapatero, Presidente del Gobierno cuando ocurrieron los hechos, en las que señala que "nunca tuvo noticia de malos tratos en Irak" y a continuación recalca su confianza en que el Ministerio de Defensa aclarará el caso.

Mariano Casado, Secretario General de la Asociación Unificada de Militares Españoles, en un artículo publicado en este mismo periódico y en la misma fecha, concluye: "en todo caso es seguro que la sociedad civil a la que las Fuerzas Armadas sirven no permanecerá inactiva ante hechos tan graves como los que se recogen en la grabación". A esto añadiremos que el Ministerio de Defensa puso automáticamente la información en manos de un juez militar, puesto que atañe necesariamente a su jurisdicción, toda vez que las Fuerzas Armadas son las más interesadas en depurar responsabilidades, pues son las más damnificadas por estos hechos.

Según nos informan desde el Ministerio de Defensa, se han abierto diligencias previas por el Juzgado Togado Militar no 12 de Madrid, que es el que está llevando a cabo la información. De momento el caso está sub júdice. 
1 Realidad que, en cierta manera, podemos encontrar reflejada en la Constitución hoy vigente en España, la de 1978, cuyo título preliminar, artículo 8.1, indica: "Las Fuerzas Armadas, constituidas por el Ejército de Tierra, la Armada y el Ejército del Aire, tienen como misión garantizar la soberanía e independencia de España, defender su integridad territorial y el ordenamiento constitucional" (Hervada y Zumaquero, 1980, p. 367).

2 B.O.E. núm. 33, sábado 7 de febrero de 2009.

3 Sobre el trabajo de la Cooperación española citaremos Agencia de Cooperación Internacional para el Desarrollo (2010). Por lo que se refiere a las ONGs, Ribera Rodríguez (2009) y VV. AA. (2010).

4 Toda vez que se establece, desde su título, una clara identificación sobre la coordinación actual entre Defensa y paz citaremos ahora el libro de López Mora y Ballesteros Martín (2011).

5 Motivadas sobre todo por violaciones o por partos precariamente atendidos.

6 Hace años un grupo de españolas viajamos a distintos países de Europa

\section{BIBLIOGRAFÍA}

Agencia de Cooperación Internacional para el Desarrollo (2010). 1995-2010: 15 años de cooperación española en los Balcanes, Madrid, Ministerio de Asuntos Exteriores y de Cooperación.

Colomer Viadel, A. (1997). Nuevo orden internacional y la solución de conflictos, Madrid, Centro de Estudios Políticos y Constitucionales.

Fernández, F. (1996). "Entrevista a...", Revista Española de Defensa 101-102.

Fernández Vargas, V. y Rodríguez Toubes, J. (coords.) (2008). La Cultura de la Defensa Nacional en España, Arbor CLXXXIX, anejo 2.

Fernández Vargas, V. (2011). "La Cultura de la Defensa y la paz en España desde una perspectiva de género". En López Mora, F. y Ballesteros Martín, M. A, Ensayos sobre la Cultura de la Defensa y la Paz en la España actual, Servicio para analizar cómo estaba organizada la atención a las mujeres en sus distintos Servicios Sociales; en Austria y en Alemania nos informaron de cómo las mujeres inmigrantes musulmanas solo acudían a los servicios sanitarios si iban a ser atendidas por mujeres.

7 Creado por acuerdo del Consejo de Ministros en marzo del año 2005. En aquella fecha era Ministro de Defensa don José Bono.

8 Sobre la conflictividad histórica en esta zona recordaremos el atentado de Sarajevo (1914) que se suele considerar desencadenante de la Primera Guerra Mundial, cometido por un militante del grupo nacionalista Joven Bosnia.

9 Parece pertinente incluir, como ya hemos hecho anteriormente, una primera aportación bibliográfica: Colomer Viadel (1997); Pérez Casado (1988, 1998 a, 1998b, 2000) y "Entrevista a Ricard Pérez Casado" en VV. AA. (2005).

10 Aprobada el 31 de octubre del año 2000 por el Consejo de Seguridad de Naciones Unidas.

de Publicaciones de la Universidad de Córdoba / Ministerio de Defensa, pp. 157-169.

Fernández Vargas, V. (2011b). “Notas sobre la Resolución 1325 del CS de las NNUU y su aplicación en España". Documento de Opinión 29/2011, Instituto Español de Estudios Estratégicos.

Hervada, J. y Zumaquero, J. M.a (1980). Textos constitucionales españoles. 1808-1978, Pamplona, EUNSA.

López Mora, F. y Ballesteros Martín, M. A. (eds.) (2011). Ensayos sobre la Cultura de la Defensa y la Paz en la España actual, Servicio de Publicaciones de la Universidad de Córdoba / Ministerio de Defensa.

Pérez Casado, R. (1988). Conflicte, tolerancia $i$ mediaciones conferencies de l'Administrador europeu a Mostar, Barcelona-Palma, Afers Carratosa.
11 Atentados que, como ya hemos indicado, en tanto que consideran el cuerpo del terrorista como parte del armamento, se separan radicalmente del anarquismo europeo; recordaremos ahora el atentado en Madrid de Mateo del Corral (1906) con motivo de la boda de Alfonso XIII que causó cerca de cien victimas mortales. Cf. Fernández Vargas (2011).

12 Para todo esto nos remitimos a Revista Española de Defensa 267, 2010.

13 Miguel González, El País, 17 de marzo 2013, p. 1.

14 El País, 19 de marzo 2013, p. 30.

15 En otro artículo, cuyo autor es también Miguel González, el cual señala que "El Ministerio de Defensa investigará las "deplorables" imágenes de soldados españoles". También en este periódico ( $E$ I País, 18 de marzo 2013, p. 10) se recogen imágenes del Manual sobre Irak del Ejercito Español (2003).

16 El País, 20 de marzo 2013, p. 21.

Perez Casado, R. (2000). "Algunas reflexiones en torno a los conflictos yugoslavos", Sistema. Revista de Ciencias Sociales 157.

Pérez Casado, R. (1998a). "La ciudad y la guerra: el caso de Mostar", Res Publica 4.

Pérez Casado, R. (1998b). "Una mirada sobre Bosnia y la antigua Yugoslavia", Ayer 31.

Ribera Rodríguez, M. (2009). Libro Blanco de la actuación en los Balcanes del movimiento por la paz, Madrid, FundiPax.

VV. AA. (2005). Dayton 10 años después. Tiempo de Paz 79.

VV. AA. (2010). Balcanes: la construcción de la paz y la democracia. Tiempo de Paz 97. 